\title{
Percepçóes sobre as mudanças nas atividades cotidianas e nos papéis ocupacionais de mulheres no climatério
}

\author{
Michelle Rodrigues Cardoso ${ }^{a}$, Maria José Gugelmin de Camargo ${ }^{b}$ \\ aPrograma Saúde da Mulher do Hospital de Clínicas, Universidade Federal do Paraná - UFPR, Curitiba, PR, Brasil. \\ bDepartamento de Terapia Ocupacional, Universidade Federal do Paraná - UFPR, Curitiba, PR, Brasil.
}

\begin{abstract}
Resumo: O climatério é definido como o processo natural do ciclo de vida feminino, inerente à transição da fase reprodutiva para a fase não reprodutiva, e tem o seu marco principal com a menopausa. Durante esse período, a mulher perpassa por várias mudanças fisiológicas, emocionais, sociais e econômicas, que podem impactar negativamente nas atividades exercidas. Com o objetivo de analisar as percepções e os significados atribuídos pelas mulheres atendidas no Ambulatório de Climatério do HC-UFPR sobre o impacto nas atividades cotidianas e nos papéis ocupacionais, realizou-se uma pesquisa exploratória e qualitativa através de um questionário estruturado com dados socioeconômicos, contendo também um check-list autoaplicável e uma entrevista semiestruturada, com aferição dos dados através de técnicas de análise de conteúdo. Observou-se que o preconceito social e o desconhecimento pela mulher sobre as mudanças ocorridas nessa fase se constituem em barreiras para realização de diversas atividades, afetando os cuidados necessários com a saúde e, consequentemente, prejudicando a sua qualidade de vida. Em contrapartida, nesse período, muitas mulheres apresentam maior habilidade de adaptação, descobrindo novas atividades, realizando planos adiados e desempenhando novos papéis ocupacionais. Constata-se a importância da compreensão sobre as mudanças, as percepções e os significados do climatério pela própria mulher e pelos profissionais, para a formulação de uma assistência integral e na qual se valorize a sua individualidade.
\end{abstract}

Palavras-chave: Climatério, Saúde da Mulher, Atividades, Papéis Ocupacionais.

\section{Perceptions on daily activities changes and occupational roles of women in climacteric stage}

\begin{abstract}
The climacteric stage is defined as the natural process of the female life cycle, it is inherent to the transition from reproductive to the non-reproductive phase, with the menopause as its major milestone. In this period, women go through several physiological, emotional, social and economic changes that can negatively impact on the activities performed. Aiming to analyze the perceptions and meanings attributed by the women seen at the Climacteric Ambulatory of the Clinical Hospital at Federal University of Paraná, on the impact on daily activities and occupational roles, we conducted an exploratory and qualitative research using a structured questionnaire with socioeconomic data containing, as well as a self-administered checklist and semi-structured interviews, in which data analysis was made using some techniques of content analysis. We observed that social prejudice and unawareness by the woman about the changes in this phase are barriers to conducting several activities, affecting necessary health care and consequently impairing their life's quality. On the other hand, during this period, many women have greater ability to adapt, finding new activities, performing postponed plans and performing new occupational roles. It is important that women and health professionals comprehend the changes, perceptions and meanings of the climacteric stage to formulate a comprehensive care enhancing their individuality.
\end{abstract}

Keywords: Climacteric, Women's Health, Activities, Occupational Roles.

Autor para correspondência: Michelle Rodrigues Cardoso, Departamento de Terapia Ocupacional, Universidade Federal do Paraná, Av. Prefeito Lothário Meissner, 632, Bloco Didático II, Jardim Botânico, CEP 80210-170, Curitiba, PR, Brasil, e-mail: mrc.economia@gmail.com Recebido em Ago. 6, 2014; $1^{\text {a }}$ Revisão em Abr. 23, 2015; Aceito em Jun. 8, 2015. 
Mulher é bicho esquisito

Todo o mês sangra

Um sexto sentido

Maior que a razão

(LEE; CARVALHO, 1995).

\section{Introdução}

O climatério é definido como o processo natural do ciclo de vida feminino, inerente à transição da fase reprodutiva para fase náo reprodutiva, e tem o seu marco principal com a menopausa, ou seja, a última menstruação (SILVA; ARAÚJO; SILVA, 2003).

Esse fenômeno ocorre devido à falência folicular ovariana, sendo que o processo se inicia na vida intrauterina até sua exaustão progressiva durante a vida reprodutiva. O período do climatério tem o seu início aos 35 anos, porém os primeiros sintomas fisiológicos costumam aparecer aos 40 anos, período no qual ocorre uma diminuição significativa do número de folículos ovarianos e distúrbios na sincronizaçáo dos sinais neuronais no sistema nervoso central e hipotálamo (ALDRIGHI; ALDRIGHI; ALDRIGHI, 2012; FERRIANI, 1995; LORENZI et al., 2009).

Para melhor compreensão sobre a origem dos sintomas que ocorrem durante o climatério, podemos dividir as mudanças fisiológicas em três fases: a perimenopausa, menopausa e pós-menopausa.

$\mathrm{Na}$ perimenopausa, período que antecede a menopausa, com duração de um ano após a mesma, pode surgir os primeiros sintomas relacionados à exaustão ovariana e alteraçóes no eixo hipotalâmico-hipofisário-gonadal. Essas transformaçôes são responsáveis pela redução progressiva dos estrogênios e da inibina. Durante essa fase, o organismo tentará estratégias compensatórias para manter a foliculogênese, provocando o aumento dos hormônios FSH (Hormônio Folículo Estimulante) e LH (Hormônio Luteinizante) (ALDRIGHI; ALDRIGHI; ALDRIGHI, 2012; BYYNY; SPEROFF, 1996).

Como decorrência dessa tentativa de compensação, ocorrerá a maturação folicular de forma irregular, ocasionando um período de transiçáo gradual com sangramentos menstruais acíclicos, podendo ou não ocorrer ovulação, com a presença ou não dos seguintes sintomas: distúrbio do sono, depressão, alteraçôes na memória e afecçóes vasomotoras, como fogachos com ou sem sudorese (BRASIL, 2008; FERRIANI, 1995).

Especificamente quanto à menopausa, o diagnóstico é realizado a partir de 12 meses após a verificação de um período prévio de amenorreia. Apesar de ocorrerem nesse período a diminuição dos ovários e o esgotamento total dos folículos, a atividade ovariana não cessa e continua com a produção de esteroides (ALDRIGHI; ALDRIGHI; ALDRIGHI, 2012; FERRIANI, 1995).

No período de pós-menopausa, o ovário é estimulado pelo LH que sintetiza hormônios andrógenos, como a testosterona e a androstenediona; porém, como não há mais folículos, não são mais possíveis aromatases para conversão de androgênios para estrogênios. Esses hormônios irão migrar pela circulação e ocasionar mudanças na pele, no fígado, nos rins e nos tecidos adiposos (ALDRIGHI; ALDRIGHI; ALDRIGHI, 2012).

Devido às alteraçóes hormonais supracitadas e aos fatores relacionados ao ambiente e à história de vida da mulher, podem ser observados os seguintes sintomas: prolapsos genitais, incontinência urinária, atrofia dos genitais, disfunção sexual, alteraçóes no metabolismo lipídico (elevação dos níveis de colesterol e triglicérides), alteraçôes no metabolismo ósseo (osteoporose), aumento de peso, alteraçôes na pele, nos olhos, nos dentes, nos pelos e nos cabelos (ALDRIGHI; ALDRIGHI; ALDRIGHI, 2012; BRASIL, 2008).

Porém, o climatério não deve ser somente compreendido por suas alterações fisiológicas, mas também como uma etapa em que a mulher perpassa por mudanças econômicas, sociais e culturais. Dentre as mudanças mais comuns, estão a impossibilidade de ter filhos biológicos, a saída dos filhos de casa, o papel de cuidadora dos pais e a chegada da aposentadoria. As mudanças podem ser encaradas de modo positivo ou negativo, dependendo da percepção e do significado que as mulheres atribuem a estas.

O climatério pode ser percebido pela mulher, por um lado, como a chance de realizar sonhos adiados ou, por outro, como um processo de doença e finitude (BRASIL, 2008; PEREIRA; SILVA; SIQUEIRA, 2008).

Algumas mulheres irão vivenciar o climatério engajando-se em novos papéis ocupacionais e atividades prazerosas; porém, para outras, pode significar uma fase de luto em que se despedem da sua juventude, das atividades produtivas e dos papéis ocupacionais construídos ao longo de suas vidas. Essa série de rupturas com as atividades e 
os papéis ocupacionais são importantes elementos de estudo e intervenção do profissional de terapia ocupacional, que pode auxiliar na adaptação e na melhoria da qualidade de vida.

Lima e Angelo (2001) afirmam que a compreensão do climatério só é possível quando reconhecemos que cada experiência nesta fase é única, pois a vivência congrega significados diferentes para cada mulher e, dessa forma, se tornam inviáveis explicações formais baseadas em modelos universais.

A compreensão sobre as percepçóes e os significados construídos nesse período é um passo importante, pois se configura em uma estratégia para evitar generalizaçôes e sensibilizar os profissionais da área da saúde para a formulação de uma assistência integral, na qual se valorize a individualidade dessas mulheres.

\section{Referencial metodológico}

\subsection{Delineamento e instrumentos de pesquisa}

A presente pesquisa foi realizada no Ambulatório de Climatério do Hospital de Clínicas da Universidade Federal do Paraná, no período entre abril e agosto de 2013, com o objetivo de analisar as percepçóes e os significados atribuídos pelas mulheres, que recebem atendimento médico no local, sobre o impacto nas atividades cotidianas e nos papéis ocupacionais durante o processo de climatério. Almejando-se o alcance do objetivo supracitado, optou-se por uma pesquisa qualitativa e exploratória.

Para operacionalizar, dividimos a coleta de dados em dois momentos. No primeiro momento, foi aplicado um questionário de triagem com perguntas voltadas aos dados socioeconômicos das participantes, além de um check-list autoaplicável, com os principais sintomas encontrados na literatura; no segundo momento, foi aplicada uma entrevista semiestruturada, visando a possibilitar a compreensão das subjetividades e dos sentidos simbólicos que as participantes podem expressar, e, dessa forma, permite-se uma análise a partir de suas percepçóes.

\subsection{Participantes}

Participaram da pesquisa 16 mulheres que estão vivenciando o climatério, com idade entre 49 e 67 anos, e que apresentavam um ou mais sintomas relacionados ao processo fisiológico de falência ovariana, preenchendo, assim, os critérios de inclusão. Foram excluídas da pesquisa as mulheres assintomáticas ou que estão no climatério devido a procedimentos cirúrgicos e interferência medicamentosa como, por exemplos, a ooforectomia e a quimioterapia.

Quanto aos dados socioeconômicos, verificamos que $12,5 \%$ das participantes são solteiras, $50 \%$ são casadas, 12,5\% mantêm união estável e $25 \%$ são divorciadas. Também constatamos o baixo nível de escolaridade entre elas: 19\% não são alfabetizadas, $12 \%$ não completaram o Ensino Fundamental, $44 \%$ apresentam Ensino Fundamental completo, 25\% apresentam Ensino Médio completo, as demais categorias referentes a graduação e pós-graduação não foram pontuadas.

Em relação às participantes que estáo atuantes no mercado formal de trabalho, contabilizaram-se 63\% das participantes; as outras participantes dividiram-se em $25,5 \%$ de aposentadas e $12,5 \%$ recebem outros tipos de auxílio previdenciário.

O número de participantes que tem filhos é de $94 \%$ e $75 \%$ são avós, sendo que $67 \%$ relataram que os filhos e $50 \%$ que os netos ainda moram com elas. O papel de cuidadora de algum membro da família foi referido por $38 \%$.

\subsection{Análise dos dados}

Realizou-se a análise de dados através do método de análise de conteúdo, sendo dividida em três etapas: a pré-análise, a exploração do material e o tratamento de resultados: inferência e interpretação (BARDIN, 1994).

A pré-análise se constituiu na organização dos dados com a finalidade de operacionalizar e esquematizar as ideias iniciais e construir categorias que fundamentaram a interpretação final. Durante a exploraçáo do material, foi realizada sua leitura exaustiva, consolidando os conteúdos nas categorias previamente estabelecidas. Após os procedimentos citados acima, realizou-se o tratamento dos resultados obtidos, através da comparação com as dimensôes teóricas existentes (BARDIN, 1994).

\subsection{Aspectos éticos}

$\mathrm{O}$ projeto de pesquisa recebeu aprovaçáo do Comitê de Ética do Hospital de Clínicas - UFPR, em 2 de abril de 2013, através do Parecer n. ${ }^{\circ} 248.896$.

As mulheres que atenderam aos critérios de seleção foram convidadas a participar após passarem pela consulta médica e receberem informações sobre a temática e o objetivo da pesquisa, sendo que a participação foi condicionada a aceitação e assinatura do Termo de Consentimento Livre e Esclarecido - TCLE. Todas as participantes tiveram sua identidade protegida através do uso de codinomes. 


\section{Discussão}

As percepçôes e os significados atribuídos ao climatério estão fortemente relacionados com os sentimentos de bem-estar, contribuindo para o enfrentamento e a elaboração de estratégias para adaptação em relação às mudanças de atividades e papéis ocupacionais ocorridas com a chegada dessa fase.

Devido à importância de compreender esses aspectos, questionamos as participantes acerca de qual é o significado do climatério e da menopausa, e os impactos nas atividades cotidianas e nos papéis ocupacionais. As respostas foram agrupadas em dois eixos. O primeiro eixo foi intitulado de "Percepções e significados sobre o impacto do climatério nas atividades cotidianas", sendo encontradas quatro categorias principais: $1-O$ silêncio do climatério; 2 -Os sintomas; 3 - Mudanças corporais, dividindo-se em duas subcategorias: envelhecimento e sexualidade; $4-A$ menopausa. O segundo eixo foi intitulado de "As mudanças nos papéis ocupacionais e nas atividades exercidas durante o climatério" e descreve os resultados referentes às mudanças, às rupturas e aos engajamentos em papéis ocupacionais na maturidade.

\subsection{Eixo 1: Percepções e significados sobre o impacto do climatério nas atividades cotidianas}

\subsubsection{O silêncio no climatério: "Só Vivendo pra saber"}

Verificamos a imensa dificuldade em verbalizar sobre o assunto, sendo esta a nossa primeira categoria: o silêncio no climatério. Muitas dessas mulheres trouxeram a percepção de que o climatério e a menopausa não são assuntos discutidos no seu cotidiano, como podemos visualizar nos seguintes diálogos:

É meio...é difícil dizer, de explicar...mas é bem chato (risos), é bem chato (Margarida, 53 anos).

Não sei falar, não sei... Só vivendo para saber o que é, não tem explicação (Girassol, 67 anos).

Observamos a evolução em relação ao entendimento e ao debate cotidiano sobre as etapas reprodutivas do ciclo de vida da mulher; porém, a passagem da etapa reprodutiva para a etapa náo reprodutiva, apesar de ser objeto de inúmeras pesquisas, ainda é permeada de crendices e tabus no que se refere às percepçôes e aos significados culturais e sociais.
Sobre esse aspecto, os estudos de Souza (2005) mostram uma interessante dicotomia entre a fase inicial reprodutiva, a menarca, e a fase final dessa etapa, a menopausa. Apesar de essas duas etapas serem marcantes na vida das mulheres, a primeira transição é bem-vinda e muitas vezes até festejada; porém, a segunda carrega o estigma de ser o marcador do envelhecimento. Isso, numa sociedade em que é constrangedor envelhecer, pode transformar o climatério e a menopausa num processo silencioso.

Atualmente, o preconceito social oriundo do climatério ainda perdura devido à crença de que o final da vida reprodutiva está associado ao final da vida produtiva. Assim, muitas mulheres ainda passam pelo climatério de forma silenciosa e com pouco acesso a informaçóes sobre as alterações físicas e emocionais decorrentes dessa fase do ciclo natural de vida (BERNI; LUZ; KOHLRAUSCH, 2007).

Valença e Germano (2010) opinam que o desconhecimento sobre as mudanças fisiológicas e emocionais envolvidas no climatério pode estar relacionado a fatores de maior adoecimento das mulheres e também ao acesso aos serviços de saúde para obtenção de atendimento e informações.

A dificuldade em definir o climatério e a falta de espaço para debater essa etapa da vida podem se revelar num sofrimento silencioso. Também pode se configurar numa barreira para o acesso às informaçôes e para a aproximaçáo social de outras mulheres que estáo passando pela mesma fase da vida.

\subsubsection{Os sintomas: "É um negócio que incomoda"}

A segunda categoria encontrada são os sintomas referentes ao climatério, que causam impactos negativos no desempenho das atividades cotidianas e também se caracterizam por ser o principal motivo de procura pelo auxílio dos profissionais da saúde, principalmente pela assistência médica.

Durante o climatério, a mulher passa por diversas mudanças físicas e psíquicas, sendo que algumas mulheres não vão referir nenhum sintoma e outras podem manifestar um conjunto de sintomas, que foi nomeado pela biomedicina como síndrome climatérica (ROCHA; ROCHA, 2010).

Com a finalidade de verificar os sintomas mais frequentes entre as participantes desta pesquisa, aplicou-se um questionário de triagem no qual foi disponibilizada uma lista dos principais sintomas encontrados na literatura.

Dentre os sintomas físicos mais citados pelas participantes, estão: ondas de calor (93,75\%), aumento de peso $(81,25 \%)$, aumento da gordura abdominal 
(81,25\%), ciclo menstrual irregular (75\%) e dores articulares (75\%). A relação total dos sintomas físicos está discriminada na Tabela 1.

As participantes também perceberam modificações emocionais e psíquicas relacionadas ao climatério, sendo as mais frequentes: ansiedade (81,25\%), irritabilidade (75\%), dificuldades de memória (75\%) e alteraçôes no ciclo de sono (68,75\%). A relação total dos sintomas emocionais se encontra na Tabela 2 .

Devido à maior possibilidade de serem descritos e também devido aos impactos negativos que repercutem no dia a dia, os sintomas foram utilizados pelas entrevistadas para explicar o significado do climatério e da menopausa. Conforme podemos constatar nos seguintes depoimentos, os sintomas apresentam a característica de atribuir a concretude dessa fase do ciclo de vida feminino, tornando-a, de certa forma, palpável para a própria mulher e perante os olhos das pessoas que as cercam.

$A i$, sei lá, eu acho um periodo muito ruim sabe? Acho que causou muita coisa assim sabe, muito calorão, muita irritação. Foi o que eu senti (Violeta, 59 anos).

É um negócio que incomoda... dá aquele calorão, aquele negócio, né! (Amor-perfeito, 55 anos).
Os sintomas, quando não controlados, podem se tornar uma grande barreira para a participaçáo nas atividades cotidianas, sendo citados nas entrevistas impactos negativos sobre o desempenho ocupacional referente às seguintes subcategorias: 1 - Gerenciamento doméstico; 2 -Participação social; 3 -Relacionamento interpessoal; 4 -Trabalho remunerado; 5 -Atividades físicas.

Os relatos das entrevistadas revelam que as atividades de gerenciamento doméstico sofreram impactos devido aos sintomas de fogachos (ondas de calor), cefaleia, formigamento, redução de memória e irritabilidade. Além desses sintomas, as participantes da pesquisa perceberam uma lentificação na execução das atividades.

Os fogachos foram apontados como uma das principais barreiras para execução das atividades de gerenciamento doméstico, devido à necessidade de interrompê-las constantemente, causando sentimento de irritação:

Quando começou eu não trabalhava fora, mas em casa, ainda sim era muito, tinha que ficar tomando banho, era demais ficava muito irritada, não conseguia realizar as tarefas domésticas (Acácia, 62 anos).

Tabela 1. Frequência de sintomas físicos associados ao climatério.

\begin{tabular}{lcl}
\hline \multicolumn{1}{c}{ Sintomas } & Número de Respostas & $\%$ \\
\hline Diminuição da acuidade auditiva & 7 & 43,75 \\
Diminuição da acuidade visual & 10 & 62,5 \\
Alteraços no paladar & 4 & 25 \\
Alterações na pele (afinamento e/ou ressecamento) & 10 & 62,5 \\
Diminuição da força muscular & 11 & 68,75 \\
Aumento do peso & 13 & 81,25 \\
Aumento da gordura abdominal & 13 & 81,25 \\
Aumento do colesterol LDL (colesterol ruim) & 11 & 68,75 \\
Doenças Cardiovasculares & 4 & 25 \\
Diabetes & 3 & 18,75 \\
Dores articulares & 12 & 75 \\
Osteoporose & 5 & 31,25 \\
Aumento da temperatura corporal & 4 & 25 \\
Ondas de Calor (fogachos) & 15 & 93,75 \\
Sudorese & 10 & 62,5 \\
Cefaleia (dores de cabeça) & 9 & 56,25 \\
Palpitações & 6 & 37,5 \\
Formigamento & 8 & 50 \\
Ciclo menstrual (irregular ou ausente) & 12 & 75 \\
Atrofia urogenital (afinamento das paredes vaginais) & 5 & 31,25 \\
Diminuição da lubrificação vaginal & 7 & 43,75 \\
Urgência miccional & 7 & 43,75 \\
Outros & 0 & 0 \\
\hline
\end{tabular}


Tabela 2. Frequência de sintomas emocionais e psíquicos associados ao climatério.

\begin{tabular}{|c|c|c|}
\hline Sintomas & $\begin{array}{l}\text { Número de } \\
\text { respostas }\end{array}$ & $\%$ \\
\hline Ansiedade & 13 & 81,25 \\
\hline Irritabilidade & 12 & 75 \\
\hline Melancolia (tristeza) & 8 & 50 \\
\hline Fadiga (cansaço) & 10 & 62,5 \\
\hline Dificuldades de concentração & 8 & 50 \\
\hline Dificuldades de memória & 12 & 75 \\
\hline Carência afetiva & 10 & 62,5 \\
\hline Insegurança & 5 & 31,25 \\
\hline Desmotivação & 6 & 37,5 \\
\hline $\begin{array}{l}\text { Ciclo do sono } \\
\text { (Insônia, sonolência durante o dia, sono com interrupções durante a noite) }\end{array}$ & 11 & 68,75 \\
\hline Depressão & 6 & 37,5 \\
\hline Diminuição da libido (desejo sexual) & 6 & 37,5 \\
\hline Outros & 0 & 0 \\
\hline
\end{tabular}

Separavich e Canesqui (2012) realizaram uma pesquisa com narrativas de mulheres que se encontram na menopausa e também detectaram que os fogachos são os principais alvos de reclamaçôes, tendo impactos negativos sobre a rotina e as ocupaçóes sociais.

As dores e os desconfortos referentes aos sintomas de cefaleia, formigamento, irritabilidade e dificuldades de memória também foram pontuados como fatores que dificultam o engajamento em atividades de gerenciamento doméstico, sendo ilustrados pelos seguintes depoimentos:

[...] tenho dor na cabeça, dor, e sinto dor faço as coisas com bastante dificuldade e dor, mas a gente tem a casa e tem que fazer, a gente tem que ficar fazendo (Orquídea, 62 anos).

[...] formigamento nas mãos teve um dia que eu não podia agachar nem levantar a mão (Orquídea, 62 anos).

Ai fica, porque eu fico é mais nervosa, qualquer coisa me irrita não tenho muita paciência, então eu acho, porque fica muito ruim (Violeta, 59 anos).

Eu esqueço das coisas, as coisas custa a voltar no meu pensamento (Orquídea, 62 anos).

Também se percebeu a lentificação ao executar as atividades em comparação à fase anterior ao climatério:

Eu faço as atividades do dia-a-dia normal, a casa eu tenho cachorro, eu tenho papagaio, eu tenho roupa pra lavar, pra passar, calçada... não mais com aquela né...quando eu pegava e fazia, eu faço em etapas né, mas faço, mais lento (Azaléia, 54 anos).
É sempre tem algumas coisas assim que a gente deixa de fazer...É, mais é aquelas atividades do dia-a-dia, até às vezes lavar uma louça a gente vai empurrando, deixando pra mais tarde, mais tarde, né...coisas assim banais que a gente às vezes deixa de fazer, não porque não dá vontade entendeu? Sinto mais dificuldade (Margarida, 55 anos).

Umas das estratégias que podem ser utilizadas para facilitar no manejo das atividades de gerenciamento doméstico é a reorganização da rotina em conjunto, com o fracionamento das tarefas a serem realizadas, possibilitando o alívio de possíveis sentimentos de sobrecarga e incompetência por não conseguirem realizá-las com a mesma facilidade e velocidade de antes.

As atividades de participação social e relacionamento interpessoal também sofreram impactos negativos devido aos sintomas de fogachos, fadiga e irritabilidade.

Além do desconforto que os fogachos costumam trazer, muitas das entrevistadas também referiram constrangimento em frequentar locais públicos:

Começou a me dar calorão, comecei a me sentir assim, como vou dizer...não me sinto bem para ir nos lugares, me passa aqueles caloröes e eu não me sinto a vontade (Amarílis, 49 anos).

A fadiga foi relacionada ao processo de climatério e menopausa, causando diminuição da vontade de participar de atividades sociais consideradas significativas e prazerosas anteriormente.

Sei lá, não gosto de sair de casa, não quero sair de casa, né. Antes eu gostava de sair, eu era muito de ir em grupo de oração, não tenho mais vontade. Sinto mais canseira, a idade pesa... a menopausa [...] (Azaléia, 54 anos). 
O relacionamento interpessoal também foi comprometido devido ao sintoma de irritabilidade que, aparentemente, não surge por um fator específico, tornando-se de difícil entendimento principalmente para os familiares próximos. Para evitar os conflitos, uma das participantes relatou uma dinâmica de isolamento e de não expressão dos seus sentimentos:

Fico irritada com minha filha que mora em casa, a sorte que ela viaja muito, se não acho que a gente ia brigar... a gente não briga porque ela sai cedo que nem hoje eu nem vi ela, acho que a gente ia discutir coisa que a gente nunca fazia... mas a gente tem uma relação boa... Com meu marido eu fico quieta, quando ele fala alguma coisa pra mim eu fico quieta... ou eu vou pro banheiro chorar ou eu fico lá pra fora pra não brigar, porque por causa de uma coisinha vai surgindo, um desgaste e não precisa, eu acho (Azaléia, 54 anos).

O entendimento da fase do climatério pelas mulheres torna-se essencial para minimizar possíveis conflitos interpessoais ocasionados pelos sintomas. As autoras Leite et al. (2013) observaram que, quando a mulher e demais pessoas do seu convívio desconhecem os aspectos dessa fase, as relaçóes familiares e com o seu círculo de amizade podem ser afetadas negativamente.

As dificuldades para se engajar nas atividades exigidas pelo trabalho remunerado foram relacionadas aos sintomas de fadiga, diminuição da força muscular, depressão, osteoporose, dificuldades com a memória e fogachos. É o que se constata no depoimento de uma das participantes, que percebeu suas dificuldades em realizar as atividades do seu trabalho, relacionando-as aos sintomas de fadiga e diminuição da força muscular, muitas vezes impossibilitando a conclusão das mesmas:

Alguns sintomas dificultam o dia-a-dia, muitas coisas a gente não consegue realizar do trabalho, me sinto mais cansada, a força também diminuiu (Girassol, 67 anos).

Quando questionada sobre o engajamento no trabalho remunerado, a participante que ilustra o depoimento abaixo parece buscar realização por meio da sua inserção nesta atividade; porém, a depressão que vivencia na fase do climatério, correlacionada com outras afecçôes, impossibilita que concretize seus planos:

Eu quero algo que me de esperança, algo novo, viver uma vida nova, só que os meus problemas de saúde me impedem de viver, onde eu fico meio deprimida, no dia me dá vontade, mas eu vou lá e não consigo. Eu quero comę̧ar uma vida nova, e meu problema de saúde náo me permite, eu preciso da minha mão e ela tá, não colabora, não consigo ficar tanto tempo sentada [...] (Dália, 50 anos).

Dificuldades em relação à memória foram descritas como tendo impactos negativos sobre as atividades de trabalho remunerado, requerendo mais atenção para o agendamento de compromissos:

Eu fico esquecendo as coisas, né. Às vezes tem coisa importante que a gente náo pode esquecer $e$ às vezes eu esqueço, ai sei lá sempre estou esquecendo que alguém falou alguma coisa ou então algum compromisso, as coisas marcadas a gente tem que sempre ficar olhando (Girassol, 67 anos).

Os fogachos foram referidos como motivo de desconforto perante os colegas no ambiente de trabalho, podendo ocasionar, em muitos casos, o isolamento social e o sentimento de vergonha:

Trabalho num lugar que tem bastante gente, $e$ ai sentindo o calorão você náo se sente à vontade (Amarílis, 49 anos).

As atividades remuneradas de trabalho apresentam papel fundamental sobre a autoestima e a independência, além de favorecer a participação social. Cavalcante et al. (2006) observam que as mulheres que estáo no climatério e que não vivem exclusivamente uma vida doméstica, atuando também no mercado de trabalho, tendem a se cuidar mais fisicamente, diminuindo a intensidade dos sintomas. Assim, percebe-se a necessidade de estimular tanto a participação nas atividades de trabalho como a necessidade de autoconhecimento, para que essa mulher possa ter mais controle sobre os seus sintomas.

É consenso que participação em atividades físicas é essencial para a manutenção de uma vida saudável durante o climatério, pois colabora com a prevenção de doenças coronarianas, diabetes, fogachos e depressão (LEITÃO et al., 2000). Porém, também algumas restrições e limitações, devidas à condição física, devem ser avaliadas:

Eu faço exercicios, agora parei com os problemas, artrose [...] (Girassol, 67 anos).

As afecções já estabelecidas, como a artrose, comumente desenvolvidas no climatério, podem se configurar como barreiras para o engajamento nesse tipo de atividade, necessitando de supervisão de um profissional qualificado para que sejam realizadas as adaptações pertinentes. 
O controle dos sintomas referidos acima pode ser realizado através da Terapia de Reposição Hormonal (TRH), na qual se utilizam principalmente os estrógenos, os progestógenos e sua associação, para o controle de sintomas urogenitais e vasomotores (WANNMACHER; LUBIANCA, 2004).

Apesar de a TRH estar disponível há mais de 60 anos, ainda é um tema de controvérsia entre a comunidade científica. Observa-se, entre os críticos, tanto a exaltação dos benefícios quanto dos malefícios, utilizando-se proporçôes iguais (WANNMACHER; LUBIANCA, 2004; POLONINI et al., 2011).

Na década de 1970, o uso da TRH foi extremamente repudiado devido à hipótese do aumento do risco de câncer de mama e endométrio. Em contrapartida, estudos apontavam inúmeros benefícios, como a prevenção da osteoporose, do declínio cognitivo e das doenças cardiovasculares (WANNMACHER; LUBIANCA, 2004).

Estudos baseados em evidências mostram a eficácia da TRH quanto à redução dos sintomas vasomotores (fogachos). Nesses casos, a Associação Pan-americana de saúde recomenda a utilização da terapia hormonal por curto prazo, não excedendo dois anos (WANNMACHER; LUBIANCA, 2004; POLONINI et al., 2011).

A maioria das mulheres entrevistadas, que iniciou a TRH prescrita pelos médicos do ambulatório de climatério, relatou melhora na qualidade de vida:

[...] mas só que dai tem o calor, que agora não ta muito porque eu faço tratamento mas tem isso daí, tá (Açucena, 54 anos).

\section{[...] fiquei em parafuso, mas depois da reposição fiquei muito boa (Acácia, 62 anos).}

Essa forma de terapia deve ser estabelecida em uma relação de confiança entre médico e paciente, na qual as possibilidades, os riscos e o benefício devem ser informados para que a mulher venha a usufruir com segurança da TRH.

Devido à sua complexidade, o cuidado com a saúde da mulher na fase do climatério deve ir além das terapêuticas farmacológicas. É necessário um cuidado integral, além de espaços nos quais a mulher seja ouvida e que obtenha informaçôes sobre esse estágio de vida. Dessa forma, constroem-se possibilidades e ferramentas para uma transformaçáo da sua qualidade de vida.

No Brasil, a discriminação de gênero, a desvalorização do envelhecer e a correlação cultural entre fertilidade e feminilidade fazem com que dificilmente os aspectos do climatério sejam interpretados como a passagem natural de uma fase da vida. Portanto, algumas mulheres no processo de climatério e, especialmente, aquelas mulheres que já estão na menopausa, podem ser invadidas por sentimentos de incapacidade e incompetência para desempenhar atividades cotidianas e até mesmo para elaborar e se engajar em outros projetos de vida (BRASIL, 2008).

Nesse sentido, as percepçóes e o entendimento dos sintomas inerentes ao climatério pelas mulheres podem auxiliar no processo de adaptação a essa nova etapa de vida, contribuindo para modificaçôes dos seus hábitos de vida diários, como na alimentação, no trabalho e na inserção de atividades físicas, proporcionando uma vida mais saudável (PEREIRA; SILVA; SIQUEIRA, 2008).

O Terapeuta Ocupacional pode contribuir na melhora da qualidade de vida através da reorganizaçáo da rotina, de estímulos para o engajamento de novos papéis ocupacionais e do empoderamento da mulher, para realizaçáo de atividades significativas. Essas estratégias podem ser incorporadas com a finalidade de promoção à saúde tanto para mulheres que estão no climatério e não apresentam dificuldades nas atividades cotidianas, tendo caráter preventivo, como na facilitação de adaptação a essa fase para mulheres que enfrentam barreiras de desempenho ocupacional devido a sintomas inerentes a mudanças fisiológicas e emocionais.

\subsubsection{Mudanças corporais, envelhecimento e sexualidade: "Me sinto menos mulher"}

$\mathrm{O}$ aumento da expectativa de vida entre as mulheres traz como consequência que as mesmas vivam um terço de suas vidas no período do climatério. $\mathrm{O}$ bem-estar, a autoestima e a adaptação às mudanças corporais frente às alterações ocorridas dependem de uma complexa interação com fatores pessoais, ambientais, aspiraçóes, culturais e sociais, bem como das habilidades de enfrentamento (GARCÍA-VINIEGRAS, 2003).

Monroy (2005) constata o medo que muitas mulheres apresentam ao chegar nessa etapa e serem rotuladas pejorativamente como menopáusicas ou climatéricas, correlacionando de forma controversa com determinadas características, como "mal-humorada", "histérica" "irritável" e "deprimida". O sentimento de medo é agravado em sociedades como a nossa, nas quais a juventude e a capacidade reprodutiva são mais valorizadas que a experiência e outros atributos femininos. Nesse sentido, o estudo de Santos et al. (2014) também vem afirmar que, dentro dos nossos 
padrôes culturais, o desempenho da feminilidade está vinculado à satisfação do parceiro e à capacidade de ter filhos.

García-Viniegras (2003) e Fernandez et al. (2003) corroboram com esses pensamentos e ressaltam que o climatério pode ser um período angustiante, pois a mulher torna-se vulnerável num contexto em que procuramos sempre alcançar rígidos padróes de beleza, repercutindo negativamente nas questóes relacionadas à autoestima.

No discurso das mulheres entrevistadas, também encontramos as mudanças corporais como uma categoria expressiva que se subdividiu em duas subcategorias, o envelhecimento e a sexualidade.

A percepção sobre o climatério, pelas entrevistadas citadas a seguir, evidencia sentimentos de perda em relação aos atributos de beleza e sexualidade, atribuídas à sua juventude e que lhes foram retirados durante o processo de envelhecimento:

Antes da maturidade tudo é melhor, pele melhor, cabelo melhor, né? Desejo sexual...não tenho mais nada (Azaléia, 54 anos).

É que assim, eu queria emagrecer e voltar a ter o corpo dos meus 40, 43 anos, que eu tinha um corpo bom... Eu tinha prazer em vestir uma roupa que me deixasse mais sexy vamos supor. $E$ agora eu quero cobrir, não tá mais aquele corpo bonito que eu me sinta bem com qualquer roupa, antes eu tinha. Eu me sinto incomodada porque o tempo ta passando, eu to envelhecendo e eu não queria envelhecer. Mas vou envelhecer do mesmo jeito (Dália, 50 anos).

As mudanças na imagem corporal podem afetar de modo positivo ou negativo nas mulheres em qualquer idade, sendo os marcos mais importantes a adolescência, a gestação e o climatério (MONROY, 2005). Porém, no climatério e na maturidade, as mudanças fisiológicas naturais ganham enfoque negativo, sendo caracterizadas no universo feminino por uma série de perdas, como, por exemplos, da massa óssea, da libido e da disposição (VALENÇA; GERMANO, 2010; GONÇALVES et al., 2003).

Devido aos paradigmas de beleza impostos pela sociedade, as transformaçôes corporais podem ser vistas como deformaçóes que culminam na perda da feminilidade:

Se eu engordasse e depois emagrecesse, eu voltava bem, a cintura e tudo. Agora se eu engordo e emagreço, já não emagreço na cintura vou emagrecer mais as pernas, no quadril. Ai eu fico com o tronco mais grosso e as pernas mais finas. Você entendeu? Tipo uma deformação, não engorda mais no lugar certo e emagrece no lugar que náo gostaria como mulher emagrecer para ter uma silhueta melhor, e ai a pele fica flácida, isso me deixou assim. Eu tenho facilidade de engordar e emagrecer por causa da ansiedade, dessa depressão... Às vezes eu como muito e fico meio cheinha, depois ai quando eu me sinto melhor eu faço regime, emagreço dois, três quilos e não fica mais aquilo que era antes. Deu pra entender?...Eu me sinto menos mulher (Dália, 50 anos).

A insatisfação de algumas pessoas com o seu próprio corpo na maturidade tem forte influência da concepção social e cultural de que o corpo envelhecido é feio, trazendo a sensação de que não possuem mais atrativos, restando apenas a nostalgia de um tempo de sedução (ÁVILA; GUERRA, 2007).

A supervalorização da juventude repercute na imagem corporal da mulher que vivencia o processo de climatério e, por consequência, também repercute em sua sexualidade de forma negativa, pois ela pode não se perceber como capaz de despertar desejo (OLIVEIRA et al., 2008).

A pesquisa quantitativa dos autores Tavares et al. (2015), realizada com uma amostra de 14 entrevistadas, constata que essas mulheres apresentaram prevalência de disfunçóes sexuais e outros sintomas do climatério. As causas mais relatadas que provocaram a disfunção sexual estão relacionadas a aspectos psicológicos e somatovegetativos. Dentre os fatores não fisiológicos envolvidos na vida sexual das mulheres que estáo nesta fase, destacam-se a qualidade das relaçóes interpessoais e a relação com o ambiente.

Os aspectos fisiológicos também irão influenciar negativamente na vida sexual saudável, pois a diminuição da lubrificação na fase de excitação, o afinamento e a atrofia da parede vaginal podem ocasionar dor e irritação durante as relaçôes sexuais (MONROY, 2005). Os autores Oliveira et al. (2008) e Almeida (2003) afirmam que essas alterações não afetam apenas a mulher, mas também seu parceiro, pois a mulher pode evitá-lo com medo de sentir dor e o homem também pode temer machucá-la.

Apesar das barreiras supraexpostas, não se pode excluir o desejo sexual e a função sexual do período do climatério. Deste modo, Monroy (2005) enfatiza que a sexualidade se transforma com a idade, porém não se torna menos interessante ou satisfatória.

Ressalta-se que o climatério náo pode ser responsabilizado isoladamente pelo declínio da atividade sexual, pois o que de fato se altera e pode ser confundido com a diminuição da libido é o tipo de resposta sexual, que pode se tornar mais 
lenta e menos intensa, porém esta náo resulta em insatisfação ou menor prazer (OLIVEIRA et al., 2008; LOPES, 2003).

Vislumbra-se que mudanças corporais e a sexualidade são caraterizadas como elementos perdidos durante o processo de climatério e envelhecimento. Portanto, é necessário desconstruir os mitos em torno dos padrôes de beleza e juventude, bem como informar às mulheres sobre as mudanças ocorridas em todas as fases da vida, para que essas mudanças deixem de ser elementos de medo, angústia e luto para se tornarem elementos que propiciem autoconhecimento e autonomia, em relação aos seus corpos.

\subsubsection{A menopausa: "Tem um lado bom e tem um lado ruim nisso"}

A menopausa foi uma das categorias significativas encontradas durante a análise das entrevistas, mas, para entendermos os significados e impactos ocorridos no cotidiano da mulher devido à interrupção do fluxo menstrual, é necessário compreendermos o significado do ciclo menstrual em nossa sociedade. Numa visão fisiológica, a menstruação é excreção de sangue e tecido superficial necrótico do endométrio após as quedas séricas de progesterona e estrogênios, ao final do ciclo ovariano (GUYTON; HALL, 2006). Durante o período menstrual, pode ocorrer a Síndrome Pré-Menstrual (SPM), popularmente nomeada como Tensão Pré-Menstrual (TPM); essas nomenclaturas são utilizadas para descrever um conjunto que pode incluir até 150 sintomas que ocorrem durante o ciclo menstrual. Dentre esses sintomas, podemos citar as dores abdominais, a constipação, a náusea, o vômito, a acne, as dores de cabeça, a irritabilidade, o aumento da retenção de líquidos e a mastalgia. Quando esses sintomas ocasionam prejuízos emocionais, sociais e físicos, afastando as mulheres de suas atividades e funçôes, tais sintomas são reconhecidos como doença (BENTO, 2009).

Socialmente, a menstruação tem um forte poder simbólico, significa o marco da passagem para a vida adulta e reprodutiva, a menina que se torna mulher, sendo, muitas vezes, comemorada a sua chegada, mas também é alvo de muitos tabus e mitos (SARDENBERG, 1994). Os primeiros relatos sobre a menstruação surgiram no Antigo Testamento, relacionando o fenômeno com impureza e infortúnios a quem tocasse a mulher neste período (FERNÁNDEZ et al., 2003). Desde a Antiguidade, em várias culturas, algumas atividades foram proibidas e comportamentos reprovados durante o ciclo menstrual, sendo que algumas dessas recomendações perduram até os dias de hoje. Dentre as proibiçóes, estão: “[...] não lavar a cabeça ou tomar banhos, não tocar as flores e as plantas, e não preparar certos alimentos [...]" (NATANSOHN, 2005, p. 293).

Entre mitos, tabus, rituais de passagem e sintomas observamos uma ambivalência em relaçáo à menstruaçáo, ao mesmo tempo em que ela é símbolo de fertilidade e feminilidade, também está associada a dores e restriçôes de atividades. Os relatos sobre a menopausa foram organizados em três categorias: 1-O encerramento da menstruação; 2- Elemento facilitador para o desempenho nas atividades cotidianas; e 3-A liberdade sexual.

Quando as participantes da pesquisa realizaram seus relatos sobre o encerramento da menstruação verificamos que a ambivalência de sentimentos em relação ao fenômeno torna-se muito evidente.

Tem um lado bom e tem um lado ruim nisso... o lado bom é que não tenho mais que me incomodar com as dores e o lado ruim é que fiquei assim sei lá, tudo tá meio estranho, não posso mais engravidar (Magnólia, 49 anos).

Que foi bom pra mim é que eu parei de menstruar, de me incomodar, né! Mas no resto não vejo vantagem [...] (Hortênsia, 60 anos).

Bertoni et al. (2011) concluíram que a percepção sobre a menstruação apresenta variações de acordo as etapas vivenciadas na vida das mulheres. Durante a juventude pode ser encarada como um fator limitador das atividades de vida diária, no puerpério é comum a relação da menstruação com os sentimentos de orgulho e felicidade e na menopausa podem-se externar sentimentos de felicidade pela finalizaçáo de um ciclo e ao mesmo tempo sentimentos negativos associados ao término da menstruação.

Verifica-se que o término do fluxo menstrual apresenta significado negativo devido a perda da capacidade reprodutiva podendo desencadear sentimentos de estranheza como relatado pela entrevistada de codinome Magnólia, como se o sangue fosse marcador de sua identidade e que com o encerramento deste a sua identidade também acaba sendo de certa forma perdida. Para os autores Medeiros et al. (2005) o fluxo menstrual parece ter o poder de identificar, disciplinar e classificar os corpos femininos em relação as suas idades, pois antes de menstruar você é menina, quando menstrua torna-se mulher-mãe e quando deixa de menstruar é velha.

Algumas mulheres podem experenciar ciclos menstruais extremamente dolorosos e com várias alteraçóes fisiológicas em decorrência da Síndrome Pré-menstrual, nesses casos a menopausa pode significar o término de um ciclo de sofrimento 
e um elemento facilitador para o engajamento em atividades cotidianas.

Oia, foi melhor... foi melhor em tudo. Antes sentia muita cólica e também o incomodo de menstruar (Bromélia, 60 anos).

Acho que pra mim no começo, quando eu menstruava, eu ficava meio assim, eu tinha muita dor. Então pra mim não fez falta não, foi muito bom que parou (Açucena, 54 anos).

O término das cólicas ocasionadas pelo ciclo menstrual foi sentido pelas participantes como um dos principais ganhos vindos com a menopausa. Bento (2009) expóe que a recorrência do sintoma de cólica afeta $75 \%$ das adolescentes brasileiras, sendo que em $25 \%$ dos casos ela é incapacitante. Dessa forma, compreende-se que a menopausa possa significar o fim de uma série de restriçôes para execução das atividades cotidianas e de participação social e que podemos constatar com o depoimento abaixo:

[...] mas pelo menos acabou aquelas cólicas que eu tinha, e assim era muito. Às vezes eu ficava até de cama, se tinha alguma coisa pra fazer às vezes nem ia. Às vezes tinha alguma festa $e$ aparecia a cólica, ai eu não saia mesmo ficava repousando (Açucena, 54 anos).

A menstruação pode se tornar uma barreira para o desempenho de atividades de cuidado com a saúde, especificamente a participação em atividades físicas devido aos sintomas decorrentes ou até mesmo por um medo muito popular que ronda as mulheres, o medo que ocorra os chamados "acidentes" em que o fluxo menstrual pode escorrer e manchar a roupa ocasionando constrangimento, assim algumas podem restringir ou até suprimir sua participaçáo nesse tipo de atividade nesse período. Para uma de nossas participantes a menopausa foi um elemento facilitador para execução desse tipo de atividade:

Facilitou, en faço muito exercício físico, para mim facilitou muito nisso. Quando você está menstruada e faz exercícios você não se sente a vontade. Então por um lado foi bom, na verdade pra tudo, foi bem tranquilo assim (Amarílis, 59 anos).

Durante o climatério a atividade física torna-se indispensável, pois nesta etapa ocorre o aumento da possibilidade de desenvolver desordens metabólicas ou o agravamento de doenças crônicas. Os exercícios físicos auxiliam na promoção do equilíbrio mental, emocional e físico, além de ser um excelente mecanismo contra a baixa autoestima.
Muitos autores como Costa e Gualda (2008) observaram em seus estudos a relação entre a perda da capacidade reprodutiva e o sentimento de ser "menos mulher". Apesar de o fluxo menstrual apresentar significados de feminilidade, fertilidade e juventude, uma das participantes correlacionou a menopausa com a sua liberdade sexual percebendo este elemento como um fator positivo em sua vida:

Não menstruar mais me preocupou no começo, achei que estivesse grávida, fiz exame e vi que não estava... não menstruar e não poder engravidar por um lado é bom (Amarílis, 49 anos).

Em nossa cultura judaico-cristã e patriarcal a mulher ainda é considerada como um ser inferior e toda a sua potencialidade de desenvolvimento em seu papel de mãe-sacrificada, santa e sofredora (MONTGOMERY, 1997). O lado positivo de não menstruar e encerrar sua etapa reprodutiva pode estar associado justamente com a libertação desses papéis e com a possibilidade de finalmente poder vivenciar a sua sexualidade sem ter como consequência uma gravidez indesejada.

Essa sensação de liberdade sexual com a menopausa tem um lado positivo, mas pode expor a mulher a Doenças Sexualmente Transmissíveis - DST, se estas não tiverem a oportunidade de obter informaçóes e acesso aos métodos preventivos.

\subsection{Eixo 2: "as mudanças nos papéis ocupacionais e atividades exercidas durante o climatério"}

O período do climatério é repleto de transformaçôes não apenas fisiológicas, mas também de transformaçōes que ocorrem nos papéis que as mulheres desempenham. Dessa forma, se torna necessário uma atençáo multidimensional em relação à saúde na fase do climatério (VELOSO; NERY; CELESTINO, 2014).

De acordo com os dados obtidos no ano de 2007, disponibilizados no DATASUS, a população brasileira era composta por cerca de 30 milhóes de mulheres com idades entre 35 e 65 anos, ou seja, na faixa etária correspondente ao climatério (BRASIL, 2008).

Durante todo o seu ciclo de vida a mulher necessita se adaptar às demandas do ambiente modificando o exercício de suas atividades e papéis ocupacionais. Quando chega à maturidade esta se depara com um momento crítico de sua vida ao qual deve buscar estratégias de adaptação para o enfrentamento de muitas perdas e mudanças. 
Na fase do climatério é comum que as mulheres se questionem não apenas sobre os sintomas, transformaçóes e alterações no seu organismo, mas também das mudanças ocorridas na sua mente. Esse momento necessita de compreensão pelos profissionais que prestam assistência à saúde para que a mulher possa vivenciá-lo de maneira plena e única; esse auxílio contribui para a chegada da maturidade com mais qualidade nos relacionamentos e com melhores condiçôes de saúde (ALMEIDA; LUZ; MONTEIRO, 2007).

Quando essas mudanças não são entendidas - e até mesmo chegam a ser negadas e permeadas de preconceitos -, podem conduzir a sentimentos de improdutividade, baixa autoestima e isolamento social, podendo gerar uma crise existencial (ALMEIDA; LUZ; MONTEIRO, 2007).

Dentre as mudanças críticas mais comuns nesse período, estão: a saída dos filhos de casa, a perda da capacidade de ter filhos biológicos, a morte dos pais, a viuvez e o afastamento das atividades produtivas remuneradas. Devido a esses fatores, constatamos a ruptura com quatro importantes papéis ocupacionais: mãe, filha, esposa e trabalhadora. Porém, também é nessa etapa que as mulheres podem se permitir vivenciar novos papéis ocupacionais, como os de avó e sogra.

Nesse período, algumas mulheres podem buscar a concretização de sonhos adiados devido ao acúmulo de tarefas e se engajar em novas atividades, como viagens, mudança de profissão e atividades de lazer. O envolvimento em novas atividades torna-se de suma importância para que a mulher experiencie este momento único de forma plena e afaste os possíveis sentimentos de não pertencimento e inutilidade.

\section{O documento "Estrutura da Prática da Terapia} Ocupacional: dominio e processo" define papéis ocupacionais como "[...] conjuntos de comportamentos esperados pela sociedade, modelados pela cultura e que podem ser, além disto, conceituados e definidos [...]" (AMERICAN..., 2008, p. 78). Nesta pesquisa, encontramos cinco categorias expressivas em relação às mudanças de papéis ocupacionais encontradas nessa fase da vida: 1 - O papel ocupacional de cuidadora; 2 - O papel ocupacional materno; 3 - O papel ocupacional de esposa; 4 - Opapel ocupacional de avó, e 5 - O papel ocupacional de trabalhadora.

Durante a análise dos relatos, visualizou-se a primeira categoria que se refere ao papel de cuidadora dos pais, filhos, marido e netos, historicamente impregnado em nossa sociedade como uma atribuição feminina e que também perdura na fase do climatério:
Eu ajudo a cuidar do meu pai, eu ajudei meu irmáo que morreu há dois anos com câncer na garganta, ai eu não comia, não dormia eu chegava do hospital minha cunhada ligava e eu tinha que levar ele. E meu pai é aquela pessoa, que por mais que minha mãe se for, ele tá com 86 anos, ele não incomoda, eu ajudo a cuidar mas ele não diz nem A nem B. Levar no médico é eu, vou levar pra fazer exame, é tudo eu, minha irmã é mais leiga nessas coisa né! Como eu cuidei da minha mãe, cuidei do meu pai, cuidei de um tio meu, eu prefiro eu ir e ela prefere que eu vá, eu gosto, eu me sinto útil nessa parte. Agora ele teve uma cirurgia, ele teve problema, ele caiu, machucou, amanheci no hospital e isso me faz bem, por mais cansaço que eu sinto, me faz bem...não sei se isso é bom...eu acho que é bom né? (Azaléia, 54 anos).

Tradicionalmente, o papel da mulher cuidadora dos pais, filhos e marido é esperado, sendo que a visibilidade social desse papel torna-se cada vez mais evidente na medida em que ocorre a transiçáo demográfica, com um grande número de idosos que necessita de auxílio de um familiar para realizar as atividades de vida diária (KARSCH, 2003).

Os estudos de Fraiman (2004) também indicam a possibilidade de haver a ruptura com o papel de filha com a morte dos pais ou a inversão de papéis, tornando-se cuidadora de quem antes costumava cuidar dela.

Podemos verificar, através do depoimento abaixo, que os cuidados com os filhos adoecidos ou que apresentam alguma limitação ficam sob a reponsabilidade da mulher:

Tenho que cuidar de um filho que não trabalha, que tem esquizofrenia, não trabalha, não tem renda (Jasmim, 53 anos).

O papel de cuidadora exercido pelas mulheres na fase do climatério pode ser realizado com satisfação, mas também pode ser motivo de sobrecarga e stress, já que a maioria dos cuidados realizados, nos casos de adoecimento ou incapacidade que ocorrem na família, não é distribuída entre seus membros e fica apenas como encargo da mulher.

A segunda categoria encontrada é a ruptura com o papel materno. Com a perda da capacidade de ter filhos, ao decorrer dessa etapa, a mulher pode entrar em um processo de luto e despedida da sua feminilidade, da autoestima e da autoimagem. $\mathrm{Na}$ fase do climatério, é comum que os filhos saiam de casa ou adotem padrōes diferentes do que aqueles que ela acredita ser o "correto", havendo uma sensação de ruptura com o papel de mãe (FRAIMAN, 2004). 
Eu me senti assim, como eu tava conversando com a minha irmá, "a sindrome do ninho vazio" (risos), eu senti uma perda, mas como ele é muito carinhoso não foi tão dolorido, ai quando ele ficou com ela, um periodo de três anos, agora eu vou casar mesmo, ai eu vi que eu perdi, agora é dela e não tenho mais... quando eles estavam juntos eu sentia assim, não é sério, não é um casamento, não é uma coisa séria né, e ele falou pra mim, não mãe agora quero casar, agora senti que ele está constituindo uma família e agora é uma vida, é a vida dele, agora eu sei que não posso contar com ele mais, assim agora quando eu quiser o meu filho querido náo vai estar ao meu lado. Não agora a mulher dele é a prioridade (Dália, 50 anos).

Quando minhas filhas sairam de casa foi dificil, eu tenho só uma agora, a mais velha saiu de casa, foi difícil porque ela casando morou dois anos em casa, não queria que ela se mudasse, mas é que eles queriam, eu disse né concordo, tem que ter a privacidade. Ela trabalha fora, ela viaja, não tem filho, eu cozinho pra ela, eu que lavo, eu que passo, eu lavo até o tênis do meu genro, acho que é dificil isso ai, mas eu me dou berm com ele assim sabe, eu me sinto bem nessa parte. Ai tem essa minha outra filha que é solteira ainda, tenho um enteado (risos) porque faz dezoito anos que ela namora o namorado dela, ai eu fico com ela só e meu marido (Azaléia, 54 anos).

Gomes, Meis e Marques (2014) observam que a Síndrome do Ninho Vazio pode ter conotação de morte e finitude, já que a maioria das mulheres passa boa parte de suas vidas envolvidas nos cuidados com a família e na criação dos filhos.

A saída dos filhos de casa pode estabelecer conflitos de geraçôes, pois os filhos buscam por sua autonomia e os pais procuram restabelecer os laços com seus filhos. Essa ruptura, de certa forma, é simplificada quando o filho sai "sozinho" de casa, mas, de modo geral, tende a ser mais difícil quando ele sai para constituir uma nova família, devido ao intercruzamento de novas histórias familiares. Algumas mulheres podem passar por essa ruptura com muito sofrimento, sentindo que algo foi arrancado, expressando tristeza ou até mesmo hostilidade (LUZ; LUZ, 2000).

Outro aspecto relevante encontrado nesta pesquisa foi a dificuldade na relaçấo conjugal e a ruptura com o papel ocupacional de esposa. Nesse período, uma das participantes referiu sentir a necessidade de uma atençâo maior do cônjuge, mesmo realizando atividades junto a ele:
Fica eu e o meu velho lá. Fica muito difícil, eu fico só, meu marido vê muita televisão, a gente sai às vezes juntos, a gente conversa, mas na hora que ele tá na televisão pode esquecer que tem alguém lá...ai eu fico brava [...] (Azaleia, 54 anos).

A separação também foi citada com pesares do que poderia ter ocorrido se esta decisão fosse tomada antes da maturidade:

A separaçáo foi logo no começo da menopausa, ai eu pensei assim, se eu tivesse me separado há 10 anos atrás quando aconteceu o primeiro adultério, se eu tivesse me separado naquela época, eu teria reagido, estaria melhor psicologicamente, o corpo náo teria tantos problemas como eu deixei acarretar. Os 10 anos que fiquei segurando o meu casamento, acho que eu teria força o suficiente, eu estaria mais forte, psicologicamente, emocionalmente pra levar minha vida adiante. Com o climatério eu já estava doente né! Psicologicamente, emocionalmente então foi onde eu entrei mesmo em depressão, e to ficando com dificuldade para reagir [...] (Dália, 50 anos).

A dedicação ao longo da vida e a ruptura com o papel de esposa no período do climatério se revelaram, para uma das entrevistadas, como uma barreira para se adaptar às adversidades. Nesse relato, transparece que a decisão da separação na juventude traria mais elementos para o enfrentamento da ruptura com esse papel.

Os fatores relacionados ao papel ocupacional de avó surgiram com grande frequência. Algumas participantes trazem relatos de grande felicidade ou ansiedade para o engajamento nas atividades que julgam ser inerentes a esse papel:

Eu vou ser avó, nossa não vejo a hora. Parece que é mais um filho que vai chegar, eu fico emocionada mesmo. To muito feliz, vou curtir muito, eu não curti os meus filhos, entendeu, para poder trabalhar e agora vou poder curtir mais [...] (Amarílis, 49 anos).

Cuido do meu neto não por precisar cuidar, eu vou buscar ele pra ficar um pouquinho comigo, mas não que eu precise cuidar (Tulipa, 55 anos).

Eu ainda não trabalhava, ai surgiu uma neta depois... Essa fase melhorou as coisas para mim (Bromélia, 63 anos).

Eu gosto muito de crianças, então nesse sentido assim, puxa eu to ficando velha e quando vir os netos eu vou estar mais velha ainda. $O$ caçula tem 25 anos e tá casado há 4 anos, mas também 
não quer ter filho tão cedo...Fico só na vontade vejo as outras crianças, dou presentes para as minhas sobrinhas e tudo...Fico na vontade (Dália, 50 anos).

De acordo com Araújo e Haubert (2014), com a chegada da maturidade, o papel da mulher também muda, pois, com os filhos já crescidos, ela passa de mãe a avó. Para muitas mulheres, o exercício da maternidade era vivenciado náo como uma vontade, mas sim como uma obrigação. Com a chegada dos netos, a relação de cuidados com os mesmos muda, passando de obrigação para estar mais ligada à diversão.

Porém, para outras participantes, o fato de tornar-se avó foi visto como um fardo, pois assumem atividades de educação e suprimento das necessidades básicas dos seus netos, configurando-se numa inversão de papéis ocupacionais, pois a avó acaba assumindo o papel de mãe.

\section{[...] Cuidar dos netos eu não consigo pararsentada, é uma trabalheira que só! (Amor-Perfeito, 55 anos).}

[...] Os netos. É um problema sério, a gente tem que ficar meio preparada para as crianças de hoje. Cuido de um neto que mora comigo, então ele é meio problemático, tem problemas no colégio, problemas psicológicos, então é meio complicado (Jasmim, 53 anos).

[...] Agora as netas estão comigo... Estão na fase onde ficam teimosas e eu não tenho mais paciência (Hortênsia, 60 anos).

[...] Sobrou os netos pra mim cuidar, tem um comigo e mais um da minha filha que trabalha, eu fico com eles, então dois netos que são praticamente filhos. Eu acho que era papel da minha filha, né? Cuidar dessa que não tem pai, tudo bem é uma responsabilidade minha, mas do outro é da minha filha, né? (Rosa, 54 anos).

O papel de avó na fase do climatério pode ocasionar uma sobrecarga; geralmente, isso ocorre quando seus filhos negligenciam a responsabilidade do papel de pai/mãe ou porque necessitam se ausentar para trabalhar e acabam contando predominantemente com a avó (VELOSO; NERY; CELESTINO, 2014).

A experiência vivenciada do papel ocupacional de avó esta correlacionada com a dinâmica familiar: quando os papéis são bem estruturados nesta relação, há maiores chances de que a construção desse novo papel tenha significado positivo.

O climatério e a menopausa também podem coincidir com a aposentadoria, período em que a mulher rompe com opapel ocupacional de trabalhadora. Marra et al. (2011) esclarecem que o momento da aposentadoria, para algumas mulheres, pode representar uma ruptura com a sua identidade, já que o emprego estabelece ligação e dá sentido de pertencimento, além de organizar a rotina. $O$ desligamento das atividades remuneradas acaba trazendo sentimentos de dependência e inatividade.

Essa fase pode também contribuir para o engajamento em novos papéis e atividades, porém, para uma das entrevistadas, significou a ruptura com as relaçóes sociais estabelecidas no ambiente de trabalho.
Ah, não! Eu preferia quando trabalhava! Porque nessa fase a gente fica mais caseira e náo sai muito. Quando eu trabalhava eu era mais disposta, eu saia cedo e chegava tarde, tinha mais ânimo, então para mim era melhor. Eu sinto bastante falta do trabalho, quando eu trabalhava era melhor. Sinto falta das amizades das amizades, muitas amizades né, era muito bom, sinto bastante falta das amizades (Violeta, 59 anos).

O contrário ocorreu com uma das participantes em que o engajamento no papel ocupacional de trabalhadora foi facilitado no período do climatério.

\begin{abstract}
Eu já trabalhava quando morava com os meus pais, ai depois eu parei para cuidar deles, foram 20 anos. Depois perdi minha mãe e desanimei também, fiquei dependendo da minha irmã, a gente morava no norte do Paraná, aqui no primeiro ano que eu cheguei uma sobrinha me arrumou emprego. Ai gostei, minha vida melhorou muito. Eu não queria no começo porque tinha medo de elevador o meu trabalho ficava no vigésimo segundo andar, eu não sabia andar na cidade e aprendi, agora estou bem. Acho que essa foi uma fase de superação (Açucena, 54 anos).
\end{abstract}

O trabalho remunerado configura-se num fator importante, construído e desempenhado durante o ciclo de vida adulto; além da remuneração, este pode possibilitar um espaço de aprendizagem e interação social. A ruptura com essa ocupação pode ocasionar sentimentos de não pertencimento, improdutividade e isolamento social.

\section{Considerações finais}

Em todas as fases do ciclo de vida - adolescência, idade adulta e maturidade -, a mulher busca constantes adaptações não só em decorrência das mudanças fisiológicas, mas também para atender às novas 
atividades e aos papéis ocupacionais socialmente construídos. Cada momento configura-se em um desafio, que pode ser desenvolvido com facilidade ou dificuldades, dependendo das condiçôes socioeconômicas e culturais em que ela está inserida.

Particularmente a mulher que perpassa o climatério e a maturidade encontra barreiras originadas por mitos e preconceitos, que vinculam essa fase a improdutividade e finitude da vida. Esses aspectos, aliados à escassez de espaços nos quais o assunto possa ser expresso, prejudicam ainda mais as mulheres, que desenvolvem o quadro sintomático pertinente à queda de hormônios natural dessa fase.

Os sintomas dessa fase, quando não controlados apresentam impactos negativos nas atividades de vida diária, no lazer, no trabalho e na interação social. Mesmo com a evolução tecnológica de novos fármacos e apoio terapêutico, o silêncio que impera entre as mulheres e as informações contraditórias propagadas pelo meio popular e até mesmo pela mídia são elementos que se configuram barreiras para busca e acesso desses serviços.

As rupturas e o surgimento de novos papéis ocupacionais podem ser almejados e celebrados ou vistos como um fardo, como, por exemplo, a aposentadoria: apesar de ser uma ruptura com uma atividade e um papel ocupacional exercido durante anos, também é vista como uma fase para se engajar em novas atividades. Porém, para algumas mulheres, pode significar a perda do poder aquisitivo, o isolamento social, e ocasionar sentimentos de inutilidade. $\mathrm{O}$ mesmo pode ocorrer com o papel ocupacional de avó, que pode significar um momento de felicidade e plenitude ou um fardo, pois ela terá que arcar com responsabilidades comumente não esperadas.

Constata-se que a dificuldade encontrada pelas mulheres em se engajar em novos papéis ocupacionais e atividades cotidianas náo deve ser relacionada meramente ao conjunto de sintomas e sim a um conjunto de fatores que englobam as questóes sociais, econômicas, culturais, ambientais e emocionais, no contexto em que a mulher está inserida.

\section{Agradecimentos}

Agradecemos ao Doutor Almir Antonio Urbanetz, responsável pelo Ambulatório de Climatério do HC/UFPR, por tornar esta pesquisa possível, e à Professora Rosibeth Del Carmen Muñoz Palm, pelas valorosas contribuiçóes.

\section{Referências}

ALDRIGHI, J. M.; ALDRIGHI, C. M. S.; ALDRIGHI, A. P. S. Alteraçōes sistêmicas no climatério. São Paulo: Moreira Junior, 2012.

ALMEIDA, A. B. Sexualidade no climatério. In: ALMEIDA, A. B. Reavaliando o climatério: enfoque atual e multidisciplinar. Porto Alegre: Atheneu, 2003. p. 17-29

ALMEIDA, L. H. R. B.; LUZ, M. H. B.; MONTEIRO, C.F. S. Ser mulher no climatério: uma análise compreensiva pela enfermagem. Revista Brasileira de Enfermagem, Rio de Janeiro, v. 15, n. 3, p. 370-375, 2007.

AMERICAN OCCUPATIONAL THERAPY ASSOCIATION - AOTA. Occupational Therapy Practice Framework: domain and process. The American Journal Occupational Therapy, New York, v. 63, n. 6, p. 625-683, 2008.

ARAUJO, D. C.; HAUBERT, B. B. De leitora para leitora: a presença da mulher madura e sua experiência de vida, análise de textos publicados em Marie Claire. $\mathrm{Ca}$ derno Espaço Feminino, Uberlândia, v. 27, n. 2, p. 116132, 2014.

ÁVILA, A. H.; GUERRA, M. Se o velho é outro, quem sou eu? A construção da auto-imagem na velhice. Pensamento Psicológico, Canoas, v. 3, n. 8, p. 7-18, 2007.

BARDIN, L. Análise de conteúdo. Lisboa: Edições 70, 1994.

BENTO, J. TPM sob controle. São Paulo: Editora Alaúde, 2009.

BERNI, N. I. O.; LUZ, M. H.; KOHLRAUSCH, S. C. Conhecimento, percepçóes e assistência à saúde da mulher no climatério. REBEN, Brasília, v. 60 , n. 3, p. 299-306, 2007. http://dx.doi.org/10.1590/s003471672007000300010 .

BERTONI, C. N. et al. O significado da menstruação para mulher no início do século XXI. Arquivos Médicos dos Hospitais e da Faculdade de Ciências Médicas da Santa Casa de São Paulo, São Paulo, v. 56, n. 2, p. 51-56, 2011.

BRASIL. Ministério da Saúde. Manual de atenção à muther no climatério/menopausa. Brasília, 2008.

BYYNY, R. L.; SPEROFF, F. Climatério: guia clínico de atendimento à mulher idosa. Rio de Janeiro: Revinter, 1996.

CAVALCANTE, M. B. S. et al. O climatério e sua relação com a saúde e ambiente de trabalho. RBPS, São Paulo, v. 19 , n. 3, p. 140-147, 2006. http://dx.doi. org/10.5020/18061230.2006.p140.

COSTA, G. M. C.; GUALDA, D. M. R. Conhecimento e significado cultural da menopausa para um grupo de mulheres. Revista da Escola de Enfermagem USP, São Paulo, v. 42, n. 1, p. 81-89, 2008. 
FERRIANI, R. A. Alterações hormonais no climatério: repercussóes a curto prazo. In: MARINHO, R. Climatério. Belo Horizonte: MEDSI, 1995. p. 13-22.

FRAIMAN, A. P. Coisas da idade. Alexa Cultural, São Paulo, v. 2, n. 1, p. 1-132, 2004.

GÁRCIA-VINIEGRAS, C. R. V. Climatério y bienestar psicológico. Revista Cubana de Obstetricia y Ginecologia, Habana, v. 29, n. 3, p. 8-16, 2003.

GOMES, L. A.; MEIS, C.; MARQUES, V. Menopausa, ninho vazio e subjetividade feminina: relato de atendimento numa enfermaria. Psicologia Hospitalar, Rio de Janeiro, v. 12, n. 1, p. 2-25, 2014.

GONÇALVES, R.; MERIGHI, M. A. B.; ALDRIGHI, J. M. Reflexôes sobre o climatério com enfoque no corpo, na cultura e na subjetividade. Reprodução $e$ Climatério, São Paulo, v. 18, n. 1, p. 108-112, 2003.

GUYTON, A. C.; HALL, J. E. Tratado de fisiologia médica. Rio de Janeiro: Elsevier, 2006. PMCid:PMC1860893.

KARSCH, U. M. Idosos dependentes: famílias e cuidadores. Cadernos de Saúde Pública, Rio de Janeiro, v. 19, n. 3, p. 861-866, 2003. PMCid:PMC149365.

LEE, R.; CARVALHO, R. Cor-de-rosa choque. Intérprete: Rita Lee. In: LEE, R.; CARVALHO, R. Rita Lee e Roberto de Carvalho. Rio de Janeiro: Som Livre, [1995]. 1 CD, faixa 8.

LEITÁO, M. B. et al. Posicionamento Oficial da Sociedade Brasileira de Medicina do Esporte: atividade física e saúde na mulher. Revista Brasileira de Medicina do Esporte, Niterói, v. 6, n. 6, p. 215-220, 2000.

LEITE, M. T. et al. O homem também fala: o climatério feminino na ótica feminina. Revista Eletrônica de Enfermagem, Santa Maria, v. 15, n. 2, p. 344-351, 2013.

LIMA, J. V.; ANGELO, M. Vivenciando a inexorabilidade do tempo e suas mudanças com perdas e possibilidades: a mulher na fase do climatério. Revista $d a$ Escola de Enfermagem, São Paulo, v. 35, n. 4, p. 309405, 2001.

LOPES, G. P. Sexualidade: fisiopatologia, diagnóstico e tratamento. In: FERNANDES, C. F. Menopausa: diagnóstico e tratamento. São Paulo: Segmento, 2003. p. 117-23.

LORENZI, D. R. S. et al. Assistência à mulher climatérica: novos paradigmas. Revista Brasileira de Enfermagem, Brasília, v. 62, n. 2, p. 287-293, 2009. http:// dx.doi.org/10.1590/s0034-71672009000200019.

LUZ, J. M. N. B.; LUZ, J. P. A. B. A síndrome do "ninho vazio", 2000. Disponível em: <http://csgois.web. interacesso.pt/MGFV001MASTER/textos/31/109_ texto.html>. Acesso em: 05 jul. 2013.
MARRA, A. V. et al. Imaginário, subjetividade e aposentadoria feminina. Brazilian Business Review, Vitória, v. 8, n. 2, p. 119-137, 2011.

MEDEIROS, P. F. et al. A divers(idade) em saúde para corpos femininos. Mnemosine, Rio Grande do Sul, v. 1, n. 1, p. 234-261, 2005

MONROY, A. El climaterio y SUS efectos em la mujer. Revista de Divulgación Cientifica y Tecnológica de la Universidad Veracruzana, México, v. 18, n. 1, p. 55-62, 2005.

MONTGOMERY, M. A menopausa: seus aspectos fisiológicos, psicológicos e sociais. Revista Brasileira de Medicina Psicossomática, São Paulo, v. 1, n. 1, p. 7-13, 1997.

NATANSOHN, G. L. O corpo feminino como objeto médico e "mediático". Estudos Feministas, Florianópolis, v. 13, n. 2, p. 287-304, 2005. http://dx.doi. org/10.1590/S0104-026X2005000200004.

OLIVEIRA, D. M.; JESUS, C. P.; MERIGHI, M. A. B. Climatério e Sexualidade: A compreensão dessa interface por mulheres assistidas em grupo. Texto e Contexto Enfermagem, Florianópolis, v. 17, n. 3, p. 519-526, 2008. http://dx.doi.org/10.1590/s010407072008000300013.

PEREIRA, Q. L. C.; SILVA, C. B. D. A.; SIQUEIRA, H. C. H. Processo de viver de mulheres climatéricas usuárias do Sistema Único de Saúde. Ciência, Cuidado e Saúde, Rio Grande, v. 7, n. 2, p. 224-231, 2008.

POLONINI, H. C. et al. A terapia de reposição hormonal e a saúde da mulher no climatério: riscos e benefícios. Revista APS, Juiz de Fora, v. 14, n. 3, p. 354-361, 2011.

ROCHA, M. D. H. A.; ROCHA, P. A. Do climatério à menopausa. Revista Cientifica do ITPAC, Tocantins, v. 3, n. 1, p. 24-27, 2010 .

SANTOS, S. M. P. et al. A vivência da sexualidade por mulheres no climatério. Revista de Enfermagem da UFSM, Santa Maria, v. 4, n. 1, p. 113-122, 2014.

SARDENBERG, C. De sangrias, tabus e poderes: a menstruação numa perspectiva sócio-antropológica. Revista Estudos Feministas, Rio de Janeiro, v. 2, n. 2, p. 314-344, 1994.

SEPARAVICH, M. A.; CANESQUI, A. M. Análise das narrativas sobre a menopausa de um site brasileiro da internet. Interface - Comunicação, Saúde, Educação, Botucatu, v. 16, n. 42, p. 609-622, 2012.

SILVA, R. M.; ARAÚJO, C. B.; SILVA, A. R. V. Alteraçôes biopsicossociais da mulher no climatério. RBPS, Fortaleza, v. 16, n. 1-2, p. 28-33, 2003.

SOUZA, C. L. Transição da menopausa: a crise da meia-idade idade feminina e seus desafios físicos e emo- 
cionais. Revista Brasileira de Terapia Comportamental e Cognitiva, São Paulo, v. 1, n. 2, p. 87-94, 2005.

TAVARES, K. F. et al. Prevalência de disfunçóes sexuais e outros sintomas relacionados ao climatério em mulheres na cidade de Jataí (GO, Brasil). Revista Movimenta, Goiânia, v. 8, n. 1, p. 23-29, 2015.

VALENÇA, N. C.; GERMANO, R. M. Concepções de mulheres sobre menopausa e climatério. Revista Rene, Fortaleza, v. 11, n. 1, p. 161-171, 2010.
VELOSO, L. C.; NERY, I. S.; CELESTINO, D. S. S. Mudanças biopsicossociais vivenciadas por mulheres no climatério: um reflexo da influência de gênero. $R e$ vista Saúde em Foco, Terezina, v. 1, n. 1, p. 46-71, 2014. WANNMACHER, L.; LUBIANCA, J. N. Terapia de reposição hormonal na menopausa: evidências atuais. Uso Racional de Medicamentos: Temas Selecionados, Brasília, v. 1, n. 6, p. 1-6, 2004.

\section{Contribuição dos Autores}

Michelle Rodrigues Cardoso: concepção e redação do texto, organização de fontes e/ou análises, coleta e tratamento de dados. Maria José Gugelmin Camargo: Concepção, redação e revisão do texto e organização de fontes e/ou análises. 